\title{
miR-155 mediates inflammatory injury of hippocampal neuronal cells via the activation of microglia
}

\author{
XIAO-HUA SUN ${ }^{1}$, MING-FEN SONG ${ }^{1}$, HAI-DONG SONG ${ }^{1}$, YU-WEN WANG ${ }^{1}$, MING-JIN LUO ${ }^{1}$ and LI-MING YIN ${ }^{2}$ \\ ${ }^{1}$ Department of Psychiatry, Mental Health Center, Hangzhou Seventh People's Hospital, \\ Zhejiang University School of Medicine, Hangzhou, Zhejiang 310027; ${ }^{2}$ Institute of Hematology, \\ The First Affiliated Hospital of Zhejiang Chinese Medical University, Hangzhou, Zhejiang 310006, P.R. China
}

Received December 26, 2017; Accepted August 9, 2018

DOI: $10.3892 / \mathrm{mmr} .2019 .9917$

\begin{abstract}
MicroRNA (miR)-155 has a crucial role in various cellular functions, including differentiation of hematopoietic cells, immunization, inflammation and cardiovascular diseases. The present study aimed to investigate the roles and mechanisms of miR-155 in treatment-resistant depression (TRD). A Cell Counting Kit- 8 assay and flow cytometry were performed to assess the cell viability and apoptosis of microglial cells, respectively. Western blotting and reverse transcription-quantitative polymerase chain reaction assays were used to evaluate the associated protein and mRNA expression, respectively. The results revealed that miR-155 reduced the cell viability of BV-2 microglial cells, and miR-155 enhanced the expression levels of pro-inflammatory cytokines in BV-2 microglial cells. Furthermore, conditioned medium from miR-155-treated microglia decreased the cell viability of HT22 hippocampal cells. miR-155-treated microglia increased the apoptosis of neuronal hippocampal cells by modulating the expression levels of apoptosis regulator Bax, apoptosis regulator Bcl-2, pro-caspase-3 and cleaved-caspase- 3 . The cell cycle distribution was disrupted by miR-155-treated microglia through induction of $\mathrm{S}$ phase arrest. Furthermore, the overexpression of suppressor of cytokine signaling 1 reversed the pro-apoptotic effect of activated microglia on hippocampal neuronal cells. In conclusion, the present results suggested that miR-155 mediated the inflammatory injury in hippocampal neuronal cells by activating the microglial cells. The potential effects of miR-155 on the activation of microglial cells suggest that miR-155 may be an effective target for TRD therapies.
\end{abstract}

Correspondence to: Dr Li-Ming Yin, Institute of Hematology, The First Affiliated Hospital of Zhejiang Chinese Medical University, 54 Youdian Road, Hangzhou, Zhejiang 310006, P.R. China E-mail: limingyin_789mly@163.com

Key words: microRNA-155, inflammation, treatment-resistant depression, microglia, hippocampal neuron, interleukin-6, tumor necrosis factor- $\alpha$, indoleamine 2,3-dioxygenase 1

\section{Introduction}

Depression, particularly treatment resistant depression (TRD) has become a focus and sensitive topic in neuropsychiatric research. Depression is a chronic and recurrent disease characterized by persistent low mood, including no interest in life, lack of pleasure, impaired concentration, loss of memory and the repeated idea of suicide $(1,2)$. There have been advancements in the pharmacological treatment of depression $(1,3)$; however, $>30 \%$ of depression therapies remain ineffective, which is termed TRD (4). At present, the treatment strategies for TRD, involve increasing the dosage and course of antidepressants, altering or using other antidepressants, adding synergists and combining with non-drug therapy (5). Despite clinical efforts, $\sim 90 \%$ patients with TRD experience different degrees of depression, which not only affects their quality of life; however, additionally becomes the principal cause of suicide (6-8). Furthermore, TRD significantly increases the incidence of diabetes mellitus and cardiovascular and cerebrovascular diseases, resulting in a marked increase in the disability rate and a burden on society (9).

Previously, accumulating evidence revealed that inflammation was closely associated with the occurrence, development and progression of depression (10-12). Additionally, the expression levels of peripheral inflammatory cytokines in patients with TRD were significantly higher compared with patients with curative depression $(13,14)$. Similarly, patients with depression with high peripheral inflammatory cytokines expression had a significantly lower response to therapies compared with patients with low expression of inflammatory cytokines $(15,16)$. Previous studies have demonstrated that tumor necrosis factor (TNF) antagonism may improve depressive symptoms in patients with TRD with high baseline inflammatory biomarkers $(17,18)$. These studies suggested that inflammation may participate in the development and progression of TRD.

MicroRNAs (miRs) act as a characteristic type of post-transcriptional modulators of gene expression with significant stabilization in serum (19). It has been suggested that microRNA-155 (miR-155), an important member of miRs, serves crucial roles in organism function, involving differentiation of hematopoietic cells (20), immunization (21), inflammation (22) and cardiovascular diseases (23). 
In addition, it was demonstrated that miR-155 serves as an oncogenic gene and overexpresses in various malignant tumors, including nasopharynx cancer (24), breast cancer (25), hepatocellular carcinoma (26) and gastric carcinoma (27). It has been reported that hippocampal dysfunction is associated with the occurrence of depression (28). Nevertheless, to the best our knowledge, the roles and mechanisms of miR-155 in inflammation as a result of TRD remains unclear.

In the present study, the associations between miR-155 and the inflammatory injury in TRD were analyzed. Furthermore, it was noteworthy to investigate the exact roles and mechanisms of miR-155 together with the activation of microglial cells in the inflammatory injury of TRD.

\section{Materials and methods}

Cell culture. The mouse BV-2 microglial cell line was obtained from the Cell Bank of Chinese Academy of Sciences (Beijing, China) and the mouse HT22 hippocampal neuron cell line obtained from the BeNa Culture Collection (Beijing, China). Cells were maintained in Dulbecco's modified Eagle's medium (DMEM) mixed 1:1 with Ham's F-12 (both Gibco; Thermo Fisher Scientific, Inc., Waltham, MA, USA) supplemented with $10 \%$ fetal bovine serum (Gibco; Thermo Fisher Scientific, Inc.) in a $5 \% \mathrm{CO}_{2}$ atmosphere at $37^{\circ} \mathrm{C}$.

Preparation of microglial-conditioned medium (MCM). BV-2 microglial cells were maintained in serum/glucose-free DMEM (Gibco; Thermo Fisher Scientific, Inc.) in an anoxic environment for $1 \mathrm{~h}$ at $37^{\circ} \mathrm{C}$. The cells were subsequently transferred into an anoxic incubator and reserved in the serum-free medium (Gibco; Thermo Fisher Scientific, Inc.; added with $1 \% \mathrm{~B} 27,2 \mathrm{mmol} / \mathrm{l}$ glutamine and $10 \mu \mathrm{l} / \mathrm{ml}$ penicillin-streptomycin). After $48 \mathrm{~h}$ treatment, the MCM was harvested. Centrifugation $\left(1,000 \mathrm{x} \mathrm{g} ; 1 \mathrm{~min} ; 4^{\circ} \mathrm{C}\right)$ was used to purify the obtained conditioned medium. The MCM was diluted with serum-free medium to $1: 1$. Subsequently, the MCM was used as the culture medium for hippocampal neuron cells in the subsequent experiments.

Cell grouping and transfection. Four treatment groups were prepared in the present study, including the control group (BV-2 microglial cells or hippocampal neuron cells), mimic control group [BV-2 microglial cells or hippocampal neuron cells transfected with control scrambled sequences (5'-GAGUAU GUGAGAUUAACUGGUGGC-3'; Shanghai GenePharma Co., Ltd., Shanghai, China)], miR-155 mimics group [BV-2 microglial cells or hippocampal neuronal cells transfected with miR-155 mimics (5'-UUAAUGCUAAUCGUGAUAGGG GUU-3'; Shanghai GenePharma Co., Ltd.)], and lipopolysaccharide (LPS) group. BV-2 microglial cells or hippocampal neuron cells were treated with LPS $(10 \mu \mathrm{g} / \mathrm{ml}$; dissolved in PBS; Beijing Solarbio Science \& Technology Co. Ltd., Beijing, China) for $24 \mathrm{~h}$ at $37^{\circ} \mathrm{C}$. Cells were seeded into 6-well plates at a density of $1 \times 10^{4}$ cells/well. The cells were starved overnight and then transfected with 75 pmol mimic control or miR-155 mimic using Lipofectamine ${ }^{\circledR} 3000$ (Invitrogen; Thermo Fisher Scientific, Inc.), according to the manufacturer's protocol. The cells were harvested $24 \mathrm{~h}$ after transfection and then used for subsequent experiments.
Overexpression of suppressor of cytokine signaling 1 (SOCS1) was induced by transfecting cells $\left(1 \times 10^{5}\right.$ cells $\left./ \mathrm{ml}\right)$ for $24 \mathrm{~h}$ at $37^{\circ} \mathrm{C}$ with $2.5 \mu \mathrm{g}$ pcDNA3.1-SOCS1 plasmid (Shanghai GenePharma Co., Ltd, Shanghai, China) using Lipofectamine ${ }^{\circledR}$ 3000 (Invitrogen; Thermo Fisher Scientific, Inc), according to the manufacturer's protocol. pcDNA3.1 served as the negative control.

Cell viability analysis. Cell Counting Kit-8 (CCK-8; Beyotime Institute of Biotechnology, Shanghai, China) was used to determine the cell viability of BV-2 microglial cells and hippocampal neuron cells from the four treatment groups described above. A density of $\sim 6 \times 10^{4}$ cells $/ \mathrm{ml}$ in the logarithmic phase were seeded into the wells of 96 -well plates, and subsequently incubated in a $5 \% \mathrm{CO}_{2}$ atmosphere at $37^{\circ} \mathrm{C}$ for $12 \mathrm{~h}$. The cells were maintained for 12,24 and $48 \mathrm{~h}$, respectively. Subsequently, $10 \mu \mathrm{lCCK}$ reagent was supplemented into the wells. Cells were maintained for $3 \mathrm{~h}$. A microplate reader (Bio-Rad Laboratories, Inc., Hercules, CA, USA) was used to record the absorbance at $450 \mathrm{~nm}$. Cell viability was evaluated by the percentage of cell survival compared with control.

ELISA. Commercially available ELISA kits were used to detect interleukin-6 (IL-6; cat. no. M6000B; R\&D systems), IL-10 (cat. no. M1000B; R\&D systems), TNF- $\alpha$ (cat. no. MTA00B; R\&D systems), TNF- $\beta$ (cat. no. E-EL-M1210; Elabscience, Wuhan, China) and indoleamine 2,3-dioxygenase 1 (IDO1; cat. no. CSB-EL010996MO; CUSABIO TECHNOLOGY LLC, Wuhan, China). Cell culture supernatants were added into the corresponding wells, and the wells were sealed using adhesive tape and maintained at $37^{\circ} \mathrm{C}$ for $90 \mathrm{~min}$. A total of $100 \mu \mathrm{l}$ biotinylated antibody fluids were supplemented into wells. Subsequently, the wells were sealed by adhesive tape and incubated for $60 \mathrm{~min}$ at room temperature. Chromogenic substrate was added into the wells, excluding for the blank wells. Plates were incubated for $10-15 \mathrm{~min}$ in the dark at $37^{\circ} \mathrm{C}$. Stop solution was added into each well and immediately mixed for $10 \mathrm{~min}$ at room temperature. The optical density (OD) 450 value was detected using a microplate reader (Bio-Rad Laboratories, Inc.).

Apoptosis assay. Cell apoptosis was evaluated by flow cytometry (FCM). Following washing with PBS, cells were trypsinized using $0.25 \%$ trypsin (Beyotime Institute of Biotechnology). Following centrifugation $\left(1,000 \mathrm{x} \mathrm{g} ; 1 \mathrm{~min} ; 4^{\circ} \mathrm{C}\right)$, the supernatant was removed and the cells for assessment were suspended in the incubation buffer at a density of $1 \times 10^{6}$ cells $/ \mathrm{ml}$. Cells were incubated with Annexin V-fluorescein isothiocyanate and propidium iodide (Xilong Scientific, Co., Ltd., Guangdong, China) at room temperature for $15 \mathrm{~min}$ in the dark. Cell apoptosis was subsequently assessed using a FACSCalibur flow cytometer (BD Biosciences, Franklin Lakes NJ, USA) and ModFit LT software version 2.0 (Verity Software House, Topsham, ME, USA).

Western blot analysis. Total protein was isolated from cells using NP40 lysis buffer (Beyotime Institute of Biotechnology). Protein concentration was measured using Bradford Protein Assay kit (Bio-Rad Laboratories, Inc.). Proteins (30 $\mu \mathrm{g} / \mathrm{lane})$ were separated by $12 \%$ SDS-PAGE. The separated products were transferred to polyvinylidene difluoride membranes (EMD Millipore, Billerica, MA, USA). The membranes were 
blocked with $5 \%$ skimmed milk at room temperature for $2 \mathrm{~h}$. Blotting was performed with specific primary antibodies at $4^{\circ} \mathrm{C}$ overnight: Anti-TNF- $\alpha$ (1:1,000; Abcam, Cambridge, UK; cat. no. ab6671; rabbit anti-mouse); anti-TNF- $\beta$ (1:500; Abcam; cat. no. ab106353; rabbit anti-mouse); anti-IDO1 (1:50; Abcam; cat. no. ab106134; rabbit anti-mouse); anti-apoptosis regulator Bax (Bax; 1:1,000; Abcam; cat. no. ab32503; rabbit anti-mouse); anti-apoptosis regulator $\mathrm{Bcl} 2$ (Bcl-2; 1:500; Abcam; cat. no. ab59348; rabbit anti-mouse); anti-pro-caspase-3 (1:10,000; Abcam; cat. no. ab32499; rabbit anti-mouse); anti-cleaved-caspase-3 (1:1,000; Abcam; cat. no. ab2302; rabbit anti-mouse); anti-SOCS1 (1:200; Abcam; cat. no. ab3691; rabbit anti-mouse) and anti-actin (1:5,000; Abcam; cat. no. ab179467; rabbit anti-mouse). Horseradish peroxidase-conjugated secondary antibodies (1:5,000; Abcam; cat. no. ab205718; goat anti-rabbit) were added and incubated at room temperature for $1 \mathrm{~h}$. Enhanced chemiluminescent (ECL) reagents (EMD Millipore) with an ECL system (GE Healthcare, Chicago, IL, USA) were used for the evaluation of results. Quantity One Analysis software version 4.6.2 (Bio-Rad Laboratories, Inc.) was used for densitometric analysis of the blots.

Reverse transcription-quantitative polymerase chain reaction (RT-qPCR) analysis. Total RNA was extracted from cultured cells using TRIzol ${ }^{\circledR}$ reagent (Invitrogen; Thermo Fisher Scientific, Inc.). RNA was reverse transcribed to cDNA using the BeyoRT ${ }^{\mathrm{TM}}$ First Strand cDNA Synthesis kit (cat. no. D7166; Beyotime Institute of Biotechnology), according to the manufacturer's instructions. The protocol for RT was as follows: $37^{\circ} \mathrm{C}$ for $60 \mathrm{~min}, 85^{\circ} \mathrm{C}$ for $5 \mathrm{~min}$ and then hold at $4^{\circ} \mathrm{C}$. RT-qPCR analysis was performed using a SYBR ${ }^{\circledR}$ Green PCR Master Mix kit (Takara Bio, Inc., Otsu, Japan) with an ABI 7500 Thermocycler (Applied Biosystems, Foster City, CA, USA). PCR cycles were as follows: $10 \mathrm{~min}$ pretreatment at $95^{\circ} \mathrm{C}, 93^{\circ} \mathrm{C}$ for $15 \mathrm{sec}, 67^{\circ} \mathrm{C}$ for $45 \mathrm{sec}$ ( 45 cycles), $93^{\circ} \mathrm{C}$ for $15 \mathrm{sec}, 67^{\circ} \mathrm{C}$ for $1 \mathrm{~min}, 95^{\circ} \mathrm{C}$ for $15 \mathrm{sec}$, a final extension at $75^{\circ} \mathrm{C}$ for $10 \mathrm{~min}$ and held at $4^{\circ} \mathrm{C}$. The primers were designed by Invitrogen (Thermo Fisher Scientific, Inc.): miR-155, forward: 5'-CTGTTAATGCTAATCGTGAT-3' and reverse: 5'-AACTGA CTCCTACATATTAG-3' (product 215 bp); IL-6, forward: 5'-TTC TTGGGACTGATGCTGGT-3' and reverse: 5'-CAAGTGCAT CATCGTTGTTCA-3' (product 211 bp); IL-10, forward: 5'-AGT ACAGCCGGGAAGACAAT-3' and reverse: 5'-TTTCTGGGC CATGCTTCTCT-3' (product 249 bp); TNF- $\alpha$, forward: 5'-CAG AAAGCATGATCCGCGAC-3' and reverse: 5'-GGTCTGGGC CATAGAACTGA-3' (product 224 bp); TNF- $\beta$, forward: 5'-CAT CCTGAAACCTGCTGCTC-3' and reverse: 5'-GGAGGAAAA GAGCTGGACCT-3' (product: 244 bp); IDO1, forward: 5'-GAC TGTGTCCTGGCAAACTG-3' and reverse: 5'-GTAGCTATG TCGTGCAGTGC-3' (product $233 \mathrm{bp}$ ); and actin, forward: 5'-TCTGAACTCCAACGATGCCT-3' and reverse: 5'-TCTTGT CCTTAAGCCTGGGG-3' (product $221 \mathrm{bp}$ ). Actin was used as the control of the input RNA level. Relative gene expression was determined using the $2^{-\Delta \Delta C q}$ method (29).

Statistical analysis. All experiments were repeated at least three times. The results in the present study are presented as the mean \pm standard error. All of the experimental data was analyzed by one-way analysis of variance following Dunnett's t-test method. $\mathrm{P}<0.05$ was considered to indicate a statistically significant difference.

\section{Results}

miR-155 decreases the cell viability of $B V-2$ microglial cells. The expression of miR-155 in BV-2 cells was investigated. The results demonstrated that the expression of miR-155 was upregulated by LPS stimulation (Fig. 1A; P<0.05). LPS is able to induce inflammation injury (30). It was suggested that miR-155 was closely associated with inflammation response of microglial cells. In the present study, the miR-155 mimics were transfected into BV-2 microglial cells. According to the RT-qPCR data, the expression level of miR-155 in BV-2 microglial cells was significantly increased by transfecting with miR-155 mimics compared with the mimic control (Fig. 1A; P<0.01). Furthermore, a CCK-8 assay was performed to measure the cell viability of BV-2 microglial cells in the treatment groups. As demonstrated in the results, compared with other groups, miR-155 mimics significantly decreased the cell viability of BV-2 microglial cells, particularly at $48 \mathrm{~h}$ (Fig. 1B; $\mathrm{P}<0.05$ ). The results indicated that the miR-155 reduces the cell viability of $\mathrm{BV}-2$ microglial cells.

miR-155 increases the expression levels of pro-inflammatory cytokines in BV-2 microglial cells. In order to investigate the associations between miR-155 and inflammatory injury, the expression levels of interleukin-6 (IL-6), IL-10, TNF- $\alpha$, TNF- $\beta$ and IDO1 were assessed in BV-2 microglial cells from each treatment group. On the basis of the ELISA data, significant increases were observed in the protein levels of IL-6, IL-10, TNF- $\alpha$, TNF- $\beta$ and IDO1 in BV-2 microglial cells transfected with miR-155 mimics (Fig. 2A; $\mathrm{P}<0.01$ ). Additionally, the RT-qPCR results indicated that the IL- 6, IL-10, TNF- $\alpha$, TNF- $\beta$ and IDO1 mRNA expression in BV-2 microglial cells was significantly upregulated by transfection with miR-155 mimics (Fig. 2B; $\mathrm{P}<0.01$ ). Additionally, the protein expression levels of pro-inflammatory cytokines, TNF- $\alpha$, TNF- $\beta$ and IDO1, were measured by western blotting (Fig. 3). It was revealed that miR-155 significantly increased the expression levels of TNF- $\alpha$, TNF- $\beta$ and IDO1 in BV-2 microglial cells compared with mimic controls $(\mathrm{P}<0.01)$. These results confirmed that miR-155 increased the expression levels of pro-inflammatory cytokines in BV-2 microglial cells.

miR-155 contributes to microglial-induced injury of hippocampal neuron cells. Hippocampal neuron cells were cultured with MCM in vitro. A CCK- 8 assay was conducted to assess the cell viability of hippocampal neuron cells following culture in the MCM of microglial cells that received the treatment/transfection described above. Based on the results, LPS-stimulation of microglia significantly decreased the cell viability of hippocampal neuron cells. According to the CCK-8 results, it was additionally identified that the cell viability of hippocampal neuron cells was significantly decreased by miR-155-stimulation of microglia (Fig. 4; $\mathrm{P}<0.05$ ).

miR-155 contributes to apoptosis of hippocampal neuron cells. FCM data revealed that the percentage of apoptotic cells in the miR-155 mimic-transfected hippocampal neuron group was $29.24 \%$, which was significantly increased compared with the control and mimic control groups (6.29 and $6.41 \%$, respectively; $\mathrm{P}<0.01)$. Furthermore, following treatment 

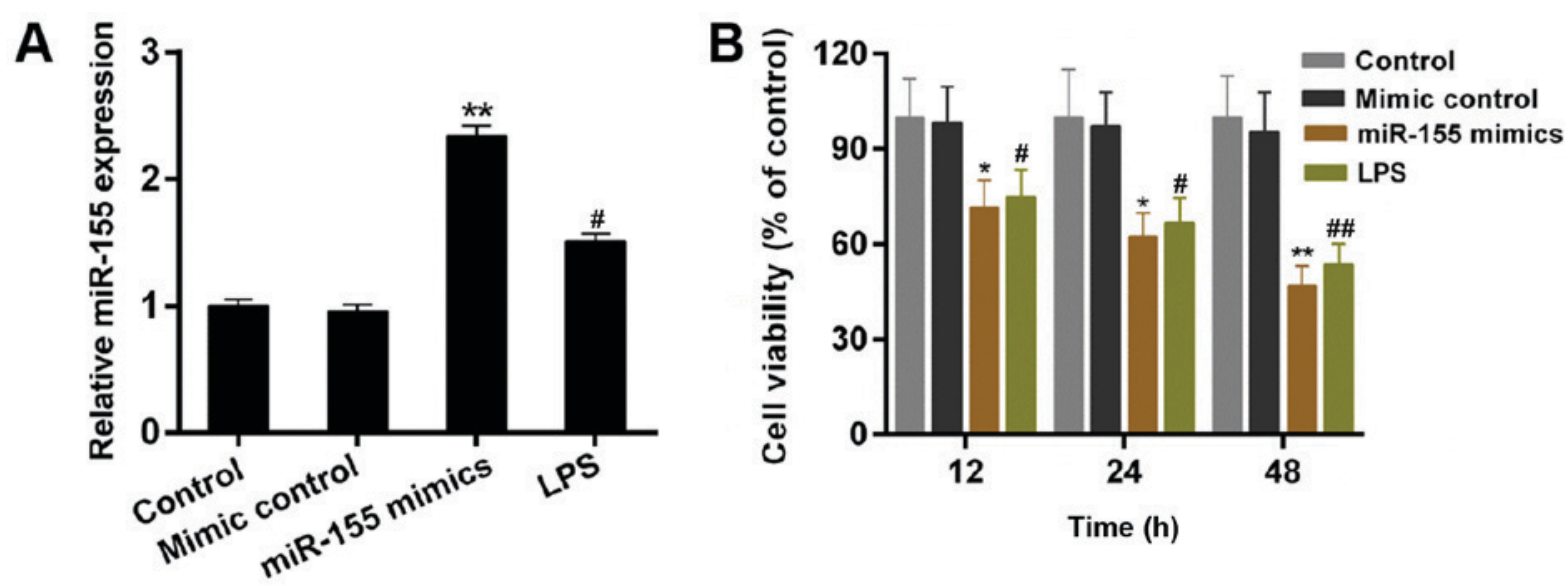

Figure 1. miR-155 increases the cell viability of BV-2 microglial cells. BV-2 microglial cells were transfected with mimic control, miR-155 mimics or treated with LPS. (A) Reverse transcription-quantitative polymerase chain reaction was conducted to determine the expression level of miR-155 in BV-2 microglial cells. (B) A Cell Counting Kit- 8 assay was performed on the cell viability of BV-2 microglial cells. ${ }^{\#} \mathrm{P}<0.05$, ${ }^{\# *} \mathrm{P}<0.01$ vs. control; ${ }^{*} \mathrm{P}<0.05$, ${ }^{* *} \mathrm{P}<0.01$ vs. mimic control. miR, microRNA; LPS, lipopolysaccharide.
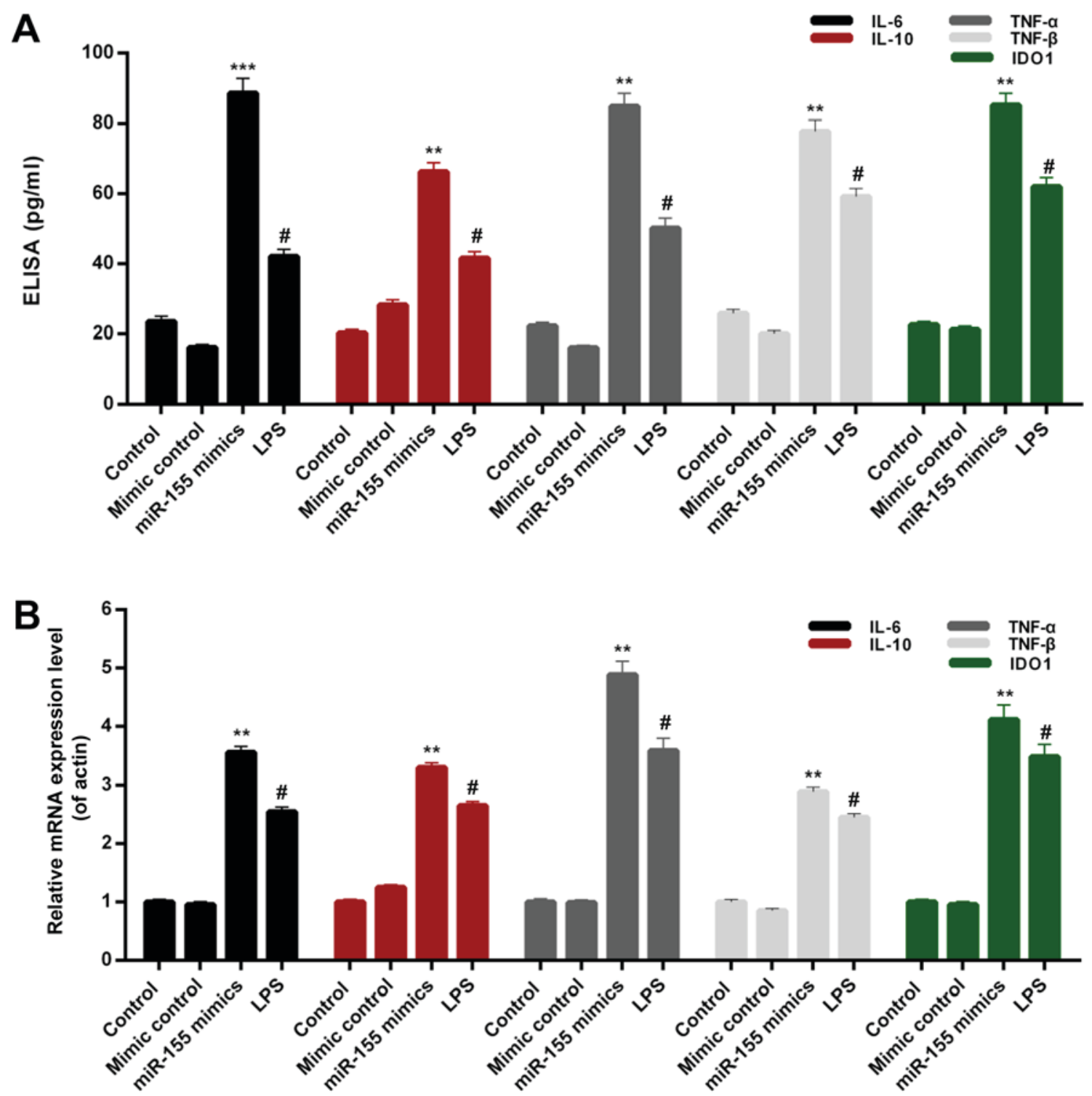

Figure 2. miR-155 increases the pro-inflammatory cytokines expression in BV-2 microglial cells. BV-2 microglial cells were transfected with mimic control, miR-155 mimics or treated with LPS. (A) ELISA and (B) reverse transcription-quantitative polymerase chain reaction assays were performed to measure the expression levels of IL-6, IL-10, TNF- $\alpha$, TNF- $\beta$ and IDO1 in BV-2 microglial cells. ${ }^{*} \mathrm{P}<0.05$ vs. control; ${ }^{* *} \mathrm{P}<0.01,{ }^{* * *} \mathrm{P}<0.001$ vs. mimic control. miR, microRNA; LPS, lipopolysaccharide; IL, interleukin; TNF, tumor necrosis factor; IDO1, indoleamine 2,3-dioxygenase 1. 

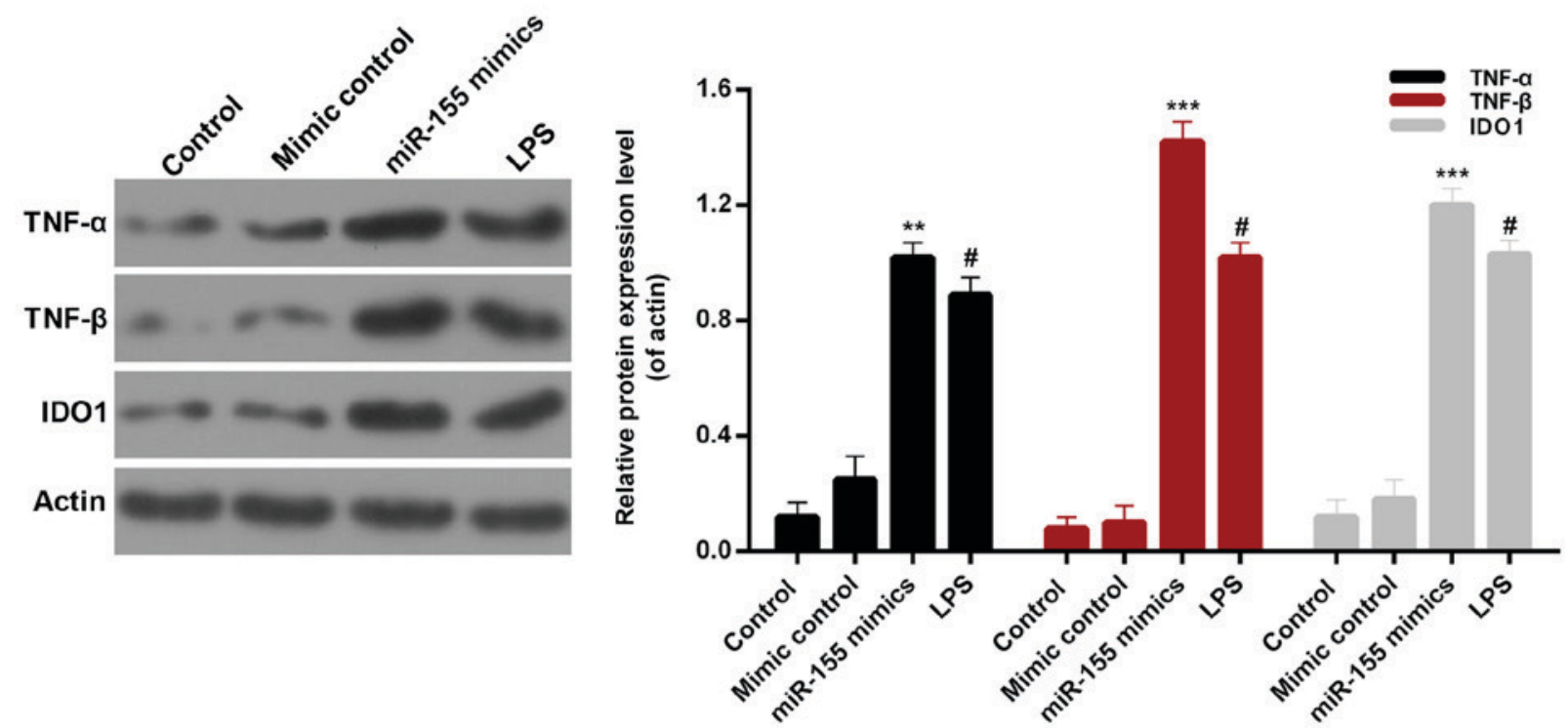

Figure 3. miR-155 upregulates TNF- $\alpha$, TNF- $\beta$ and IDO1 expression in BV-2 microglial cells. BV-2 microglial cells were transfected with mimic control, miR-155 mimics or treated with LPS. Western blotting was performed to evaluate the expression levels of TNF- $\alpha$, TNF- $\beta$ and IDO1 in BV-2 microglial cells. ${ }^{*} \mathrm{P}<0.05$ vs. control; ${ }^{* *} \mathrm{P}<0.01,{ }^{* * *} \mathrm{P}<0.001$ vs. mimic control. miR, microRNA; LPS, lipopolysaccharide; TNF, tumor necrosis factor; IDO1, indoleamine 2,3-dioxygenase 1 .

with MCM from the LPS-treated microglia, the apoptosis rate of hippocampal neuron cells was increased to $28.63 \%$. These data indicated that miR-155-stimulation of microglia significantly increased the apoptosis of hippocampal neuron cells, which was even more marked compared with the positive control (LPS; Fig. 5). In order to further investigate the associated apoptosis mechanisms in hippocampal neuron cells, the expression levels of several apoptosis-associated proteins were assessed, including $\mathrm{Bax}, \mathrm{Bcl}-2$, pro-caspase-3 and cleaved-caspase- 3 in the hippocampal neuronal cells. It was observed that the expression level of Bcl-2 in hippocampal neuronal cells was significantly decreased in the miR-155 mimics group (Fig. 6; $\mathrm{P}<0.01$ ). However, there was no significant difference in the expression level of pro-caspase-3 in hippocampal neuronal cells among the treatment groups. The western blot analysis additionally revealed similar trends in Bax, Bcl-2, pro-cleaved-3 and cleaved-caspase-3 protein expression in hippocampal neuron cells from each treatment group (Fig. 6). Based on these results, it was suggested that miR-155-stimulation of microglia modulates the expression levels of Bax, Bcl-2, pro-caspase-3 and cleaved-caspase- 3 in hippocampal neuron cells. Therefore, it was concluded that miR-155 contributed to increasing the apoptosis of hippocampal neuronal cells by modulating the levels of Bax, Bcl-2, and cleaved-caspase-3.

miR-155 promotes the cell cycle arrest of hippocampal neuron cells. The effect of miR-155 on cell cycle progression of hippocampal neuronal cells was examined. It was demonstrated that MCM from LPS-treated microglial cells decreased the cell numbers in the G1 phase and increased the cell numbers in the $\mathrm{S}$ phase compared with the control group. The cell cycle was also arrested by miR-155 group; identified by the decreasing cell numbers in the G1 phase and increasing cell numbers in the $\mathrm{S}$ phase compared with the mimics control group (Fig. 7; $\mathrm{P}<0.05$ ).

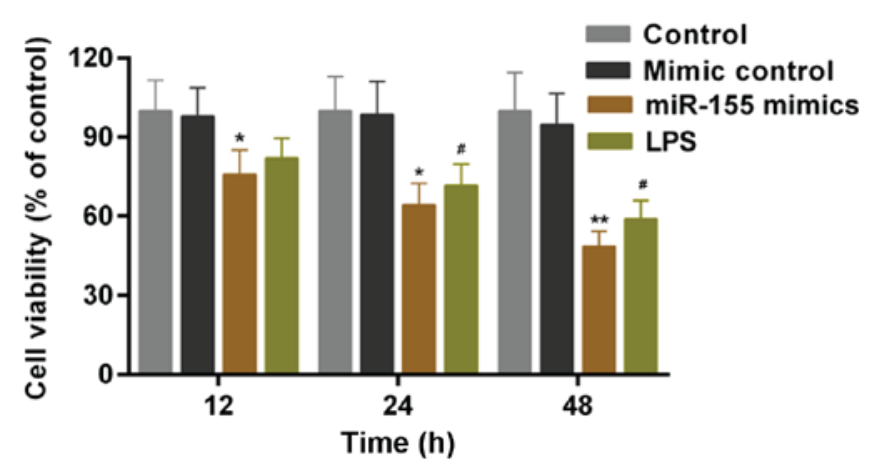

Figure 4. miR-155 reduces the cell viability of hippocampal cells. Hippocampal cells were transfected with mimic control, miR-155 mimics or treated with LPS. A Cell Counting Kit- 8 assay was performed to determine the cell viability. ${ }^{\prime \prime} \mathrm{P}<0.05$ vs. control; ${ }^{*} \mathrm{P}<0.05,{ }^{* *} \mathrm{P}<0.01$ vs. mimic control. miR, microRNA; LPS, lipopolysaccharide.

Suppressor of cytokine signaling 1 (SOCS1) is involved in the effect of miR-155. It has been reported that SOCS1 is a direct target of miR-155 during microglia activation $(31,32)$. Therefore, the function of SOCS1 was investigated in the present study. The results demonstrated that the expression of SOCS1 was reduced in the presence of miR-155 mimics (Fig. 7; P<0.05). Furthermore, the expression of Bcl-2 and Bax was upregulated and downregulated by overexpression of SOCS1 in hippocampal cells, respectively, compared with the miR-155 mimics group (Fig. 8; $\mathrm{P}<0.05$ ). It was suggested that miR-155 mediates hippocampal neuron cell injury via SOCS1.

\section{Discussion}

A principal limitation in the progression of TRD research is the lack of a useable model. Microglia are widely distributed in the central nervous system (CNS), accounting for 5-20\% of 

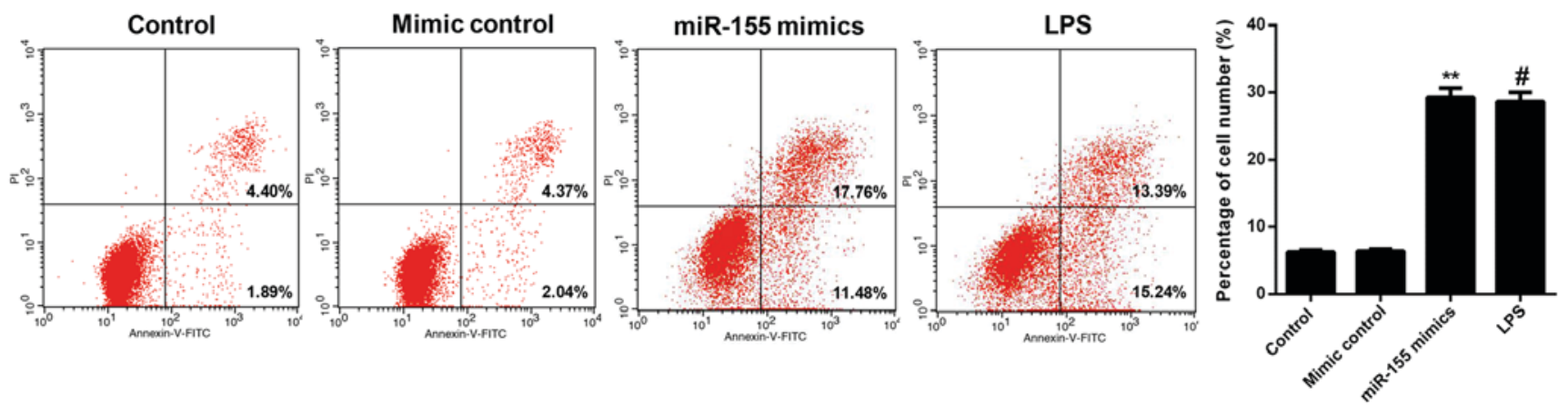

Figure 5. miR-155 enhances the apoptosis of hippocampal cells. Hippocampal cells were transfected with mimic control, miR-155 mimics, or treated with LPS Flow cytometry was performed to detect cell apoptosis of hippocampal neuronal cells. ${ }^{\prime \prime} \mathrm{P}<0.05$ vs. control; ${ }^{* *} \mathrm{P}<0.01$ vs. mimic control. miR, microRNA; LPS, lipopolysaccharide; PI, propidium iodide; FITC, fluorescein isothiocyanate.
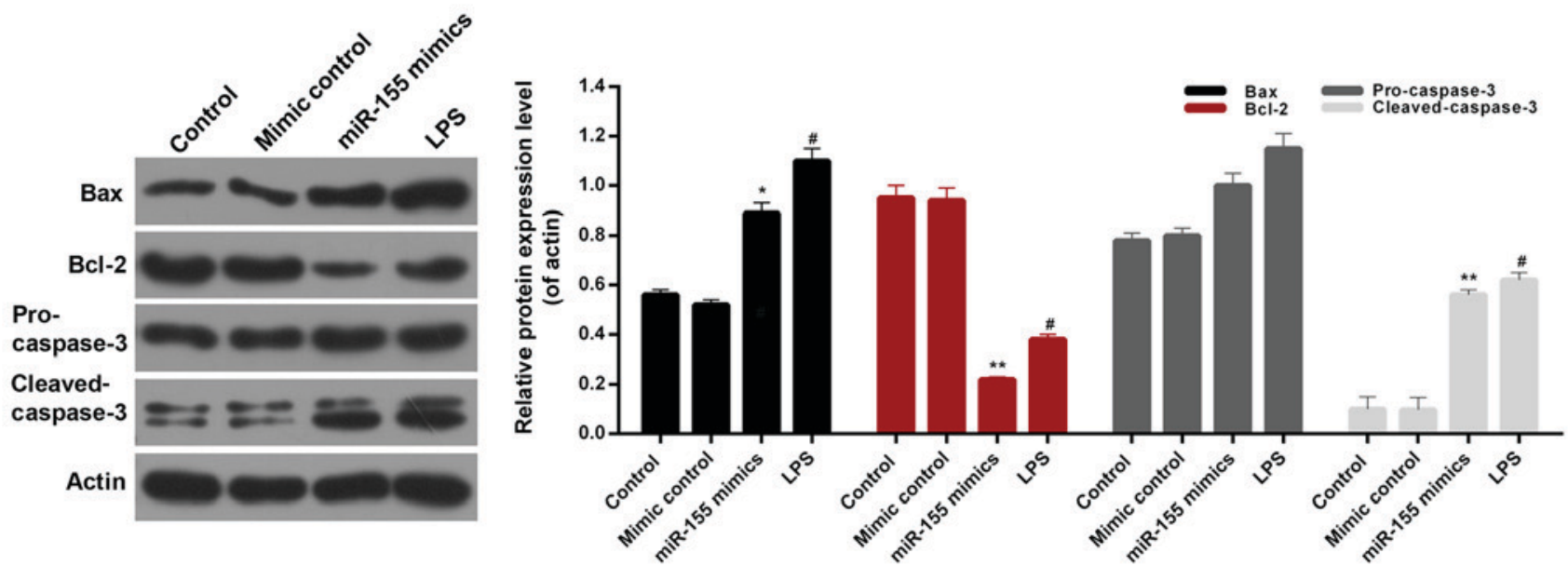

Figure 6. miR-155 modulates apoptosis-associated protein expression. Hippocampal neuronal cells were transfected with mimic control, miR-155 mimics, or treated with LPS. Western blot assays were conducted to evaluate the expression levels of Bax, Bcl-2, pro-caspase-3 and cleaved-caspase- 3 in hippocampal neuronal cells. ${ }^{*} \mathrm{P}<0.05$ vs. control; ${ }^{*} \mathrm{P}<0.05,{ }^{* *} \mathrm{P}<0.01$ vs. mimic control. miR, microRNA; LPS, lipopolysaccharide.
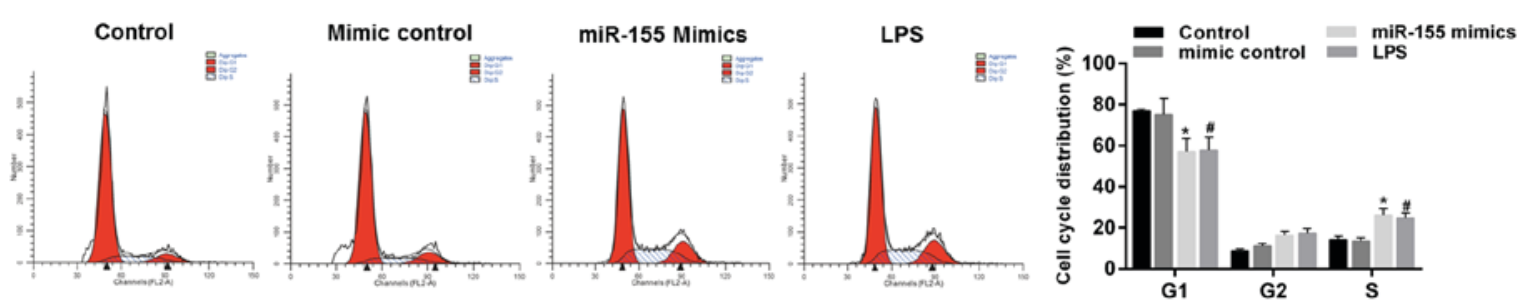

Figure 7. miR-155 promotes the cell cycle arrest of hippocampal cells. Hippocampal cells were transfected with mimic control, miR-155 mimics or treated with LPS. Flow cytometry was performed to detect the cell cycle progression of hippocampal neuronal cells. ${ }^{~} \mathrm{P}<0.05$ vs. control; ${ }^{*} \mathrm{P}<0.05$ vs. mimic control. LPS, lipopolysaccharide; miR, microRNA.

the total number of neuroglial cells. Microglia are considered the principal immune effector cells in the CNS, which act as immune supervisors at rest state (33). Due to the important immune function and wide distribution, microglia serve extremely important roles in CNS diseases. When the CNS is subjected to specific noxious stimuli, including ischemia, hypoxia, infection, trauma and chronic neuropathy, the microglia will be activated (34). Activated microglia possess can perform phagocytosis and release specific cytokines, including pro-inflammatory cytokines and neurotrophic factors (35). Common pro-inflammatory cytokines secreted by microglia are IL-1, IL- 6 and TNF- $\alpha$, which cause inflammatory reactions in the nervous system, exacerbate damage to nerve cells and promote apoptosis of nerve cells (36). Previous studies have demonstrated that microglia mediate nerve damage in CNS diseases (37). Whereas, more recently, research has indicated that activated microglia release neurotrophic factors; however, they also provide neuroprotective effects (38-40). In order to elucidate the exact role and mechanism of activated microglia in nervous system diseases, it is necessary to conduct an in-depth study on the function of microglia. On the basis of the pivotal role of microglia in 

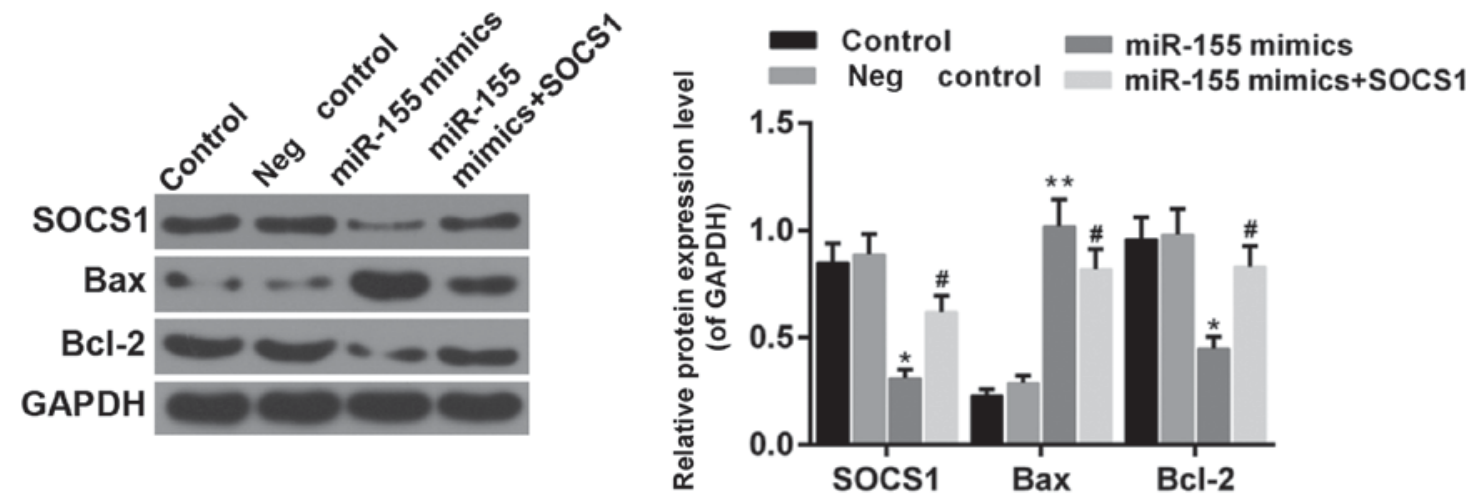

Figure 8. Overexpression of SOCS1 reverses the effect of miR-155. Hippocampal neuronal cells were transfected with negative control (mimic control + SOCS1 negative control), miR-155 mimics or miR-155 mimics + SOCS1. Western blotting was performed to evaluate the expression levels of SOCS1, Bax and Bcl-2. ${ }^{*} \mathrm{P}<0.05,{ }^{* *} \mathrm{P}<0.01$ vs. neg control; ${ }^{\#} \mathrm{P}<0.05$ vs. miR-155 mimics. miR, microRNA; SOCS1, suppressor of cytokine signaling 1; Neg, negative; LPS, lipopolysaccharide; Bax, apoptosis regulator Bax; Bcl-2, apoptosis regulator Bcl-2.

CNS, microglia were selected as the research model in the present study.

A previous study has demonstrated that miR-155 was able to modulate the microglia-mediated immune response (32). The present results demonstrated that miR-155 was increased in microglial cells by LPS stimulation. However, the roles of miR-155 in TRD remain unclear. Therefore, the present study proposed to investigate the accurate functions of miR-155 in microglia and the associated mechanisms. Initially, miR-155 mimics were subsequently transfected into the mouse BV-2 microglial cells. RT-qPCR confirmed that the expression levels of miR-155 in BV-2 microglial cells transfected with miR-155 mimics were significantly higher compared with the other treatment groups. Furthermore, the cell viability of BV-2 microglial cells from each treatment group was measured. The results indicated that miR-155 significantly reduced the cell viability of BV-2 microglial cells, even more significantly compared with the LPS positive control. The expression levels of a number of pro-inflammatory cytokines in BV-2 microglial cells from each treatment group were assessed. Based on ELISA data, miR-155 significantly increased the expression of IL-6, IL-10, TNF- $\alpha$, TNF- $\beta$ and IDO1 in BV-2 microglial cells. RT-qPCR data additionally demonstrated similar trends of the pro-inflammatory cytokines in BV-2 microglial cells. Furthermore, the protein expression levels of TNF- $\alpha$, TNF- $\beta$ and IDO1 in BV-2 microglial cells were assessed. It was observed that miR-155 significantly upregulated the expression levels of TNF- $\alpha$, TNF- $\beta$ and IDO1 in BV- 2 microglial cells. Collectively, it was concluded that miR-155 activated an inflammatory response in BV-2 microglial cells and increased the release of pro-inflammatory cytokines. A previous study has reported that knockdown of miR-155 may protect microglia against LPS-induced inflammatory injury by downregulating the expression of IL-6/8 and TNF- $\alpha$ (41). Therefore, the data from the previous study and the present study indicate that miR-155 is closely associated with the inflammatory response in microglia.

To further investigate the role of miR-155 in the CNS, the cell viability of mouse hippocampal neuronal cells cultured with MCM from each treatment group was measured. The results revealed that miR-155 significantly reduced the cell viability of hippocampal neuron cells. Furthermore, the cell apoptosis of hippocampal neuron cells was detected by FCM. On the basis of FCM data, it was observed that miR-155 significantly increased the apoptosis of hippocampal neuronal cells. The associated mechanisms of apoptosis were additionally examined. The expression levels of a number of apoptosis-associated proteins in hippocampal neuronal cells were evaluated from each treatment group. The results indicated that miR-155 significantly upregulated the expression levels of Bax and cleaved-caspase-3, and reduced the Bcl-2 expression in hippocampal neuron cells. These results confirmed that miR-155 promoted the apoptosis of hippocampal neuron cells by modulating the expression levels of Bax, Bcl-2, pro-caspase-3 and cleaved-caspase-3. Furthermore, cell cycle arrest was induced in the miR-155 group compared with the mimic control group.

SOCS1 regulates the immune response to cytokines or to other inflammatory stimuli (42). Previous studies have demonstrated that SOCS1 is a direct target of miR-155 in microglia activation $(5,31)$. Therefore, it was hypothesized that SOCS1 is associated with the microglial-induced hippocampal neuron cell injury. The present results revealed that SOCS1 was downregulated by miR-155 in microglial cells. Furthermore, the expression of Bcl-2 and Bax in hippocampal neuron cells were reversed by SOCS1 overexpression compared with the miR-155 mimics group. It was demonstrated that miR-155 mediated microglia via SOCS1 and subsequently regulated the hippocampal neuronal cell injury.

Collectively, the present research demonstrated that miR-155 mediated inflammatory injury in hippocampal neuron cells via the activation of microglial cells. The present results provide novel insight for understanding the pathogenesis of TRD and a noteworthy potential approach for the therapy of TRD.

\section{Acknowledgements}

Not applicable.

\section{Funding}

This research was supported by Zhejiang Provincial Natural Science Foundation of China (grant nos. LQ16H090008 and 
LY18H290004) and National Natural Science Foundation of China (grant no. 81601183).

\section{Availability of data and materials}

All data generated and/or analyzed during this study are included in this published article.

\section{Authors' contributions}

XHS and LMY designed the study. XHS, MFS, HDS, YWW and MJL performed the experiments. MFS, HDS and YWW performed data analysis. XHS wrote the manuscript. XHS, MFS, HDS and LMY revised the manuscript. All authors reviewed the manuscript.

\section{Ethics approval and consent to participate}

Not applicable.

\section{Patient consent for publication}

Not applicable.

\section{Competing interests}

The authors declare that they have no competing interests.

\section{References}

1. Moussavi S, Chatterji S, Verdes E, Tandon A, Patel V and Ustun B: Depression, chronic diseases, and decrements in health: Results from the World Health Surveys. Lancet 370: 851-858, 2007.

2. Nestler EJ, Barrot M, DiLeone RJ, Eisch AJ, Gold SJ and Monteggia LM: Neurobiology of depression. Neuron 34: 13-25, 2002.

3. Fava M: Diagnosis and definition of treatment-resistant depression. Biol Psychiatry 53: 649-659, 2003.

4. Trivedi MH, Rush AJ, Wisniewski SR, Nierenberg AA, Warden D, Ritz L, Norquist G, Howland RH, Lebowitz B, McGrath PJ, et al: Evaluation of outcomes with citalopram for depression using measurement-based care in STAR*D: Implications for clinical practice. Am J Psychiatry 163: 28-40, 2006.

5. Carvalho AF, Berk M, Hyphantis TN and McIntyre RS: The integrative management of treatment-resistant depression: A comprehensive review and perspectives. Psychother Psychosom 83: 70-88, 2014.

6. Conwell Y and Brent D: Suicide and aging. I: Patterns of psychiatric diagnosis. Int Psychogeriatr 7: 149-164, 1995.

7. Kochanek KD, Murphy SL, Anderson RN and Scott C: Deaths: Final data for 2002. Natl Vital Stat Rep 53: 1-115, 2004

8. Weissman MM, Bland RC, Canino GJ, Greenwald S, Hwu HG, Joyce PR, Karam EG, Lee CK, Lellouch J, Lepine JP, et al: Prevalence of suicide ideation and suicide attempts in nine countries. Psychol Med 29: 9-17, 1999.

9. Petersen T, Gordon JA, Kant A, Fava M, Rosenbaum JF and Nierenberg AA: Treatment resistant depression and axis I co-morbidity. Psychol Med 31: 1223-1229, 2001.

10. Lopresti AL, Maker GL, Hood SD and Drummond PD: A review of peripheral biomarkers in major depression: The potential of inflammatory and oxidative stress biomarkers. Prog Neuropsychopharmacol Biol Psychiatry 48: 102-111, 2014.

11. Miller AH and Raison CL: The role of inflammation in depression: From evolutionary imperative to modern treatment target. Nat Rev Immunol 16: 22-34, 2016.

12. Rethorst CD, Bernstein I and Trivedi MH: Inflammation, obesity, and metabolic syndrome in depression: Analysis of the 2009-2010 National health and nutrition examination survey (NHANES). J Clin Psychiatry 75: e1428-e1432, 2014.
13. Maes M, Bosmans E, De Jongh R, Kenis G, Vandoolaeghe E and Neels H: Increased serum IL-6 and IL-1 receptor antagonist concentrations in major depression and treatment resistant depression. Cytokine 9: 853-858, 1997.

14. Sluzewska A, Sobieska M and Rybakowski JK: Changes in acute-phase proteins during lithium potentiation of antidepressants in refractory depression. Neuropsychobiology 35: 123-127, 1997.

15. Lanquillon S, Krieg JC, Bening-Abu-Shach U and Vedder H: Cytokine production and treatment response in major depressive disorder. Neuropsychopharmacology 22: 370-379, 2000.

16. Mikova O, Yakimova R, Bosmans E, Kenis G and Maes M: Increased serum tumor necrosis factor alpha concentrations in major depression and multiple sclerosis. Eur Neuropsychopharmacol 11: 203-208, 2001.

17. Raison CL, Rutherford RE, Woolwine BJ, Shuo C, Schettler P, Drake DF, Haroon E and Miller AH: A randomized controlled trial of the tumor necrosis factor antagonist infliximab for treatment-resistant depression: The role of baseline inflammatory biomarkers. JAMA Psychiatry 70: 31-41, 2013.

18. Weinberger JF, Raison CL, Rye DB, Montague AR, Woolwine BJ, Felger JC, Haroon E and Miller AH: Inhibition of tumor necrosis factor improves sleep continuity in patients with treatment resistant depression and high inflammation. Brain Behav Immun 47: 193-200, 2015.

19. Sochor M, Basova P, Pesta M, Dusilkova N, Bartos J, Burda P, Pospisil V and Stopka T: Oncogenic microRNAs: miR-155, miR-19a, miR-181b, and miR-24 enable monitoring of early breast cancer in serum. BMC Cancer 14: 448, 2014.

20. Garzon R and Croce CM: MicroRNAs in normal and malignant hematopoiesis. Curr Opin Hematol 15: 352-358, 2008.

21. Leng RX, Pan HF, Qin WZ, Chen GM and Ye DQ: Role of microRNA-155 in autoimmunity. Cytokine Growth Factor Rev 22: 141-147, 2011.

22. Teng G and Papavasiliou FN: Shhh! Silencing by microRNA-155. Philos Trans R Soc Lond B Biol Sci 364: 631-637, 2009.

23. Staszel T, Zapala B, Polus A, Sadakierska-Chudy A, Kieć-Wilk B, Stepien E, Wybranska I, Chojnacka M and Dembinska-Kiec A: Role of microRNAs in endothelial cell pathophysiology. Pol Arch Med Wewn 121: 361-366, 2011.

24. Zhu X, Wang Y, Sun Y, Zheng J and Zhu D: MiR-155 up-regulation by LMP1 DNA contributes to increased nasopharyngeal carcinoma cell proliferation and migration. Eur Arch Otorhinolaryngol 271: 1939-1945, 2014.

25. Zhang CM, Zhao J and Deng HY: MiR-155 promotes proliferation of human breast cancer MCF-7 cells through targeting tumor protein 53-induced nuclear protein 1. J Biomed Sci 20: 79, 2013.

26. Zhang L, Wang W, Li X, He S, Yao J, Wang X, Zhang D and Sun X: MicroRNA-155 promotes tumor growth of human hepatocellular carcinoma by targeting ARID2. Int J Oncol 48: 2425-2434, 2016.

27. Wu Q, Jin H, Yang Z, Luo G, Lu Y, Li K, Ren G, Su T, Pan Y, Feng B, et al: MiR-150 promotes gastric cancer proliferation by negatively regulating the pro-apoptotic gene EGR2. Biochem Biophys Res Commun 392: 340-345, 2010.

28. Tang MM, Lin WJ, Pan YQ, Guan XT and Li YC: Hippocampal neurogenesis dysfunction linked to depressive-like behaviors in a neuroinflammation induced model of depression. Physiol Behav 161: 166-173, 2016.

29. Livak KJ and Schmittgen TD: Analysis of relative gene expression data using real-time quantitative PCR and the 2(-Delta Delta C(T)) method. Methods 25: 402-408, 2001.

30. Stayte S, Rentsch P, Tröscher AR, Bamberger M, Li KM and Vissel B: Activin a inhibits MPTP and LPS-induced increases in inflammatory cell populations and loss of dopamine neurons in the mouse midbrain in vivo. PLoS One 12: e0167211, 2017.

31. Zheng X, Huang H, Liu J, Li M, Liu M and Luo T: Propofol attenuates inflammatory response in LPS-activated microglia by regulating the miR-155/SOCS1 pathway. Inflammation 41: 11-19, 2018.

32. Cardoso AL, Guedes JR, Pereira de Almeida L and Pedroso de Lima MC: miR-155 modulates microglia-mediated immune response by down-regulating SOCS-1 and promoting cytokine and nitric oxide production. Immunology 135: 73-88, 2012.

33. Wake $\mathrm{H}$ and Fields RD: Physiological function of microglia. Neuron Glia Biol 7: 1-3, 2011.

34. Filipovic R and Zecevic N: Neuroprotective role of minocycline in co-cultures of human fetal neurons and microglia. Exp Neurol 211: 41-51, 2008.

35. Hanisch UK: Microglia as a source and target of cytokines. Glia 40: 140-155, 2002. 
36. Smith JA, Das A, Ray SK and Banik NL: Role of pro-inflammatory cytokines released from microglia in neurodegenerative diseases. Brain Res Bull 87: 10-20, 2012.

37. Kreutzberg GW: Microglia: A sensor for pathological events in the CNS. Trends Neurosci 19: 312-318, 1996.

38. Mizuno T, Doi Y, Mizoguchi H, Jin S, Noda M, Sonobe Y, Takeuchi H and Suzumura A: Interleukin-34 selectively enhances the neuroprotective effects of microglia to attenuate oligomeric amyloid- $\beta$ neurotoxicity. Am J Pathol 179: 2016-2027, 2011.

39. Noda H, Takeuchi H, Mizuno T and Suzumura A: Fingolimod phosphate promotes the neuroprotective effects of microglia. J Neuroimmunol 256: 13-18, 2013.

40. Polazzi E and Monti B: Microglia and neuroprotection: From in vitro studies to therapeutic applications. Prog Neurobiol 92: 293-315, 2010
41. Yin $\mathrm{H}$, Song $\mathrm{S}$ and Pan X: Knockdown of miR-155 protects microglia against LPS-induced inflammatory injury via targeting RACK1: A novel research for intracranial infection. J Inflamm (Lond) 14: 17, 2017.

42. Yoshimura A, Nishinakamura H, Matsumura $Y$ and Hanada T: Negative regulation of cytokine signaling and immune responses by SOCS proteins. Arthritis Res Ther 7: 100-110, 2005.

(c) (i) () This work is licensed under a Creative Commons Attribution-NonCommercial-NoDerivatives 4.0 International (CC BY-NC-ND 4.0) License. 